\title{
NIOBIUM CARBIDE COMPOSTIE COATINGS ON SS304 USING LASER ENGINEERED NET SHAPING (LENS ${ }^{\text {TM}}$ )
}

Thomas Gualtieri and Amit Bandyopadhyay

W. M. Keck Biomedical Materials Research Laboratory

\begin{abstract}
In this study, niobium carbide - stainless steel 304 (SS304) metal matrix composite was processed using laser engineering net shaping (LENS). By laser bonding $\mathrm{NbC}$ particles with $\mathrm{SS} 304$, the $\mathrm{NbC}$ dispersed at the grain boundaries and in the lattice. XRD results showed that $\mathrm{NbC}$ addition caused lattice strain, which resulted in the strengthening of the matrix metal, increase hardness, and a $>75 \%$ decrease in wear rate. The carbides became abrasive particles in the metal during wear, which increased the wear resistance along with the coefficient of friction (COF). Such coating approach via LENSTM could be utilized in specific locations to protect existing steel parts or be added to new ones that may be sensitive to wear degradation as opposed to treating the entire part surface.
\end{abstract}

Keywords: Hard coating, laser deposition, wear degradation, additive manufacturing, LENS ${ }^{\text {TM }}$. 


\subsection{Introduction}

Metal matrix composites (MMC) have been of interest for use as protective coatings due to their high hardness and wear resistance [1]. These coatings benefit from the ductile matrix of the metal, but are reinforced by a hard ceramic phase. NbC has incredible hardness (-17-22GPa), high wear resistance, and a high melting temperature $\left(3873^{\circ} \mathrm{C}\right)[2]$, [3]. It is a group VB element which are known to make very hard phases in many common alloys [3]. Unlike other carbides between group IV to VI such as titanium, vanadium, and chromium, $\mathrm{NbC}$ has been given little attention towards hard coatings application [3]. In the past, $\mathrm{NbC}$ has been researched to be used to make wear resistant coating using thermal reactive diffusion[2]. $\mathrm{NbC}$ has also shown that it could be deposited using a Nb:YAG laser, as well as be mixed in situ to form a wear resistant MMC bonded using a IPG fiber laser [1], [4]. In this study, NbC was tested to see if it was an effective additive to make protective metal ceramic composites when bonded with SS304. It was hypothesized that LENS ${ }^{\mathrm{TM}}$ could deposit a coating of NbC in SS304 to make a MMC with increased hardness and wear resistance.

\subsection{Experimental Procedure}

2.1 LENS Processing: NbC powder was purchased from American Elements ${ }^{\circledR}$ with 99\% purity and a particle size of -100/+270 mesh. 304/304L (SS304) powder was bought from Carpenter $^{\circledR}$ with a powder size of $-140 /+325$ mesh. The composition of the powder is listed in Table 1. They were then mixed in proportions of 5 and 10 wt. $\%$ of NbC For the rest of this paper, the coatings will be referred to by their respective $\mathrm{NbC}$ content. LENS ${ }^{\mathrm{TM}}$ processing was used to deposit coating of 0,5 , and $10 \mathrm{wt} . \%$. LENS $^{\text {TM }}$ operates by depositing powder using a $\mathrm{Nb}$ :YAG laser in an argon environment. It is then melted and solidifies on the substrate. A more 
detailed description of LENS ${ }^{\mathrm{TM}}$ can be found in our previous work [5]. Two layers were deposited in a $10.6 \mathrm{~mm}$ x $14.7 \mathrm{~mm}$ rectangle for each specimen. For each mixture another sample was made that had an empty laser pass after the last layer was deposited.

2.2 Characterization: After polishing and etching the samples, microstructure was imaged using a field emission scanning electron microscope (FEI Quanta 200, OR). Hardness test were done along the cross section of the coatings using a Vickers microhardness tester (HMV-2T, Shimadzu, Kyoto, Japan). A load of $0.9807 \mathrm{~N}$ and a dwell time of 15 s were used. A Nanovea series tribometer (Microphotonics Inc., CA. USA) was used to measure the wear rate and COF. A silicon nitride ball with a $3 \mathrm{~mm}$ diameter was used for linear reciprocating wear tests on the coatings. Tests were done with a $5 \mathrm{~N}$ load, $1200 \mathrm{~mm} / \mathrm{min}$ speed, $1000 \mathrm{~m}$ distance, and $10 \mathrm{~mm}$ stroke length in DI water at room temperature. Wear rate was calculated from analysis of the wear track width. COF was calculated from the tribometer's force sensors data.

\subsection{Results and Discussion}

3.1 Microstructure: Figure 1 is an image of microstructures of NbC coatings on SS304. LENS $^{\text {TM }}$ processing of SS304 resulted in small grains with more homogeneous morphology due to faster cooling rate [5], [6]. There was a significant difference in grain size between the laser pass and non-laser pass samples. The grain structures look very similar, with equiaxed morphology and carbides on the grain boundaries. The laser pass has been known to refine, homogenize, and cause dissolution of coarse carbides [7]. This effect can be seen in the $10 \% \mathrm{NbC}$ sample. The non-laser pass has the carbides spread throughout the grain structure, and the grains had more variable morphology. After the laser pass, the grains became more homogeneous. The 
laser pass was also effective in densifying the coating surface, which resulted in increased hardness and wear resistance. Moreover, $\mathrm{NbC}$ forms solid solutions in iron, which means that some $\mathrm{NbC}$ most likely diffused into the grains [3]. It is known that carbide dispersion directly affects the strength of a coating [8] because it causes lattice strain which increases hardness and wear resistance [9]-[12]. This strain is being caused by $\mathrm{NbC}$ precipitates on the grain boundaries as well as within the lattice.

\begin{abstract}
3.2 XRD Analysis: $\mathrm{NbC}$ has an FCC structure with carbon occupying the interstitial positions[13]. Figure 2 shows that the SS304 was all FCC- Fe based on peaks present at $43.8^{\circ}$, $51^{\circ}$, and $74.8^{\circ}$ (ICSD: 53803, ICDD: 98-005-3803) [14]. The NbC peaks are at $34.7^{\circ}, 40.3^{\circ}$, $58.3^{\circ}$, and $69.7^{\circ}$ (ICSD: 601142, ICDD: 98-060-1142)[15]. The main peaks slightly shift due to lattice strain from $\mathrm{NbC}$ addition [16].
\end{abstract}

3.3 Hardness Measurements: Average hardness values of the top surface of the coatings are reported in Figure 3. With higher $\mathrm{NbC}$ content, the hardness increased. Likewise the laser pass densifying the top surface also increased hardness as has been see before[7]. The $5 \% \mathrm{NbC}$ raised the hardness by $25.2-25.6 \mathrm{HV}_{0.1}$ and $10 \% \mathrm{NbC}$ by $57.0-58.6 \mathrm{HV}_{0.1}$. The difference in hardness between the laser pass and non-laser pass was small, though in all cases, laser pass samples showed higher hardness.

\title{
3.4 Wear Studies: Figure 4 shows the averages of the COF after $200 \mathrm{~m}$. All the coatings
} were roughly the same and on average 0.1 above the SS304. The dispersed carbides were the reason for this increase in $\mathrm{COF}$. The $\mathrm{NbC}$ precipitates and its presence on the grain boundary left 
small very hard particles dispersed throughout the structure. These hard particles caused extra abrasion in the metal matrix, and increased the COF. The dispersed carbides also increased the wear resistance by $77-84 \%$. Figure 5 shows the normalized wear rates of the samples. NbC addition caused a significant reduction in wear rate. Addition of $\mathrm{NbC}$ prevented damage to the underlying material by causing more abrasion on the wear ball. Such coating approach via LENS $^{\mathrm{TM}}$ could be utilized in specific locations to protect existing steel parts or be added to new ones that may be sensitive to wear degradation as opposed to treating the entire part surface.

\author{
4.0 Summary \\ Laser melting was able to deposit $\mathrm{NbC}$ reinforced SS304 composite coatings that \\ exhibited higher hardness and improved wear resistance. Laser processing of NbC in the SS304 \\ yielded smaller and more homogenous grains. $\mathrm{NbC}$ particles increased both hardness and wear \\ resistance. The addition of a laser pass further increased those properties along with densification \\ the coatings. NbC reinforced SS304 decreased the wear rate of the matrix SS304 by $>75 \%$.
}

\title{
Acknowledgments
}

Authors would like to thank Anish Shivaram, Bryan Heer, and José Marcial for help with SEM, lab work, and XRD analysis. Authors would like to acknowledge financial support from the Joint Center for Aerospace Technology Innovation (JCATI, Seattle, WA) and the US National Science Foundation under the grant number CMMI 1538851. Tom Gualtieri also likes to acknowledge his one year fellowship support from the Hydro Research Foundation (CO, USA). 


\section{References}

[1] Q. Li, Y. Lei, and H. Fu, "Laser cladding in-situ NbC particle reinforced Fe-based composite coatings with rare earth oxide addition," Surf. Coat. Technol., vol. 239, pp. 102-107, 2014.

[2] U. Sen, "Kinetics of niobium carbide coating produced on AISI 1040 steel by thermoreactive deposition technique," Mater. Chem. Phys., vol. 86, no. 1, pp. 189-194, 2004.

[3] M. Woydt, H. Mohrbacher, J. Vleugels, and S. Huang, "Niobium carbide for wear protection - tailoring its properties by processing and stoichiometry," Met. Powder Rep., vol. 00, no. 00, 2016.

[4] M. Sansone, A. De Bonis, A. Santagata, J. V Rau, A. Galasso, and R. Teghil, "Pulsed laser ablation and deposition of niobium carbide," Appl. Surf. Sci., 2015.

[5] A. Bandyopadhyay, S. Dittrick, T. Gualtieri, J. Wu, W. M. K. Biomedical, and M. Engineering, "Calcium phosphate - titanium composites for articulating surfaces of loadbearing implants," J. Mech. Behav. Biomed. Mater., vol. 57, pp. 280-288, 2016.

[6] S. S. Chakraborty, H. More, V. Racherla, and A. K. Nath, “Journal of Materials Processing Technology Modification of bent angle of mechanically formed stainless steel sheets by laser forming," J. Mater. Process. Tech., vol. 222, pp. 128-141, 2015.

[7] V. K. Balla and A. Bandyopadhyay, "Surface modification of AISI 410 stainless steel using laser engineered net shaping (LENSTM)," Mater. Des., vol. 30, no. 5, pp. 14901496, May 2009.

[8] M. T. Marques, V. Livramento, J. B. Correia, A. Almeida, and R. Vilar, "Production of copper - niobium carbide nanocomposite powders via mechanical alloying,” vol. 399, pp. $382-386,2005$. 
[9] W. Pang, H. C. Man, and T. M. Yue, "Laser surface coating of Mo-WC metal matrix composite on Ti6Al4V alloy," Mater. Sci. Eng. A, vol. 390, no. 1-2, pp. 144-153, Jan. 2005.

[10] D. Novichenko, a. Marants, L. Thivillon, P. Bertrand, and I. Smurov, "Metal matrix composite material by direct metal deposition," Phys. Procedia, vol. 12, no. PART 1, pp. 296-302, 2011.

[11] Y. Schneider, E. Soppa, C. Kohler, R. Mokso, and E. Roos, "Numerical and experimental investigations of the global and local behaviour of an $\mathrm{Al}(6061) / \mathrm{Al} 2 \mathrm{O} 3$ metal matrix composite under low cycle fatigue," Procedia Eng., vol. 10, pp. 1515-1520, 2011.

[12] a. Glage, M. Weider, M. Hasterok, a. Weidner, K. Eigenfeld, C. G. Aneziris, and H. Biermann, "Mechanical properties of metal matrix composites based on TRIP steel and ZrO2 ceramic foams,” Procedia Eng., vol. 10, pp. 548-555, 2011.

[13] A. Orjuelag, R. Rincón, and J. Jairo, “Corrosion resistance of niobium carbide coatings produced on AISI 1045 steel via thermo-reactive diffusion deposition," Surf. Coat. Technol., vol. 259, pp. 667-675, 2014.

[14] A. E. Lindh and A. Westgren, "Zeitschrift fuer Physikalische Chemi," Leipzig, vol. 102, pp. 1-25, 1922 .

[15] O. Kanzaki, Y.;Shiota, Y.;Yaguchi, Y.;Matsumoto, "No Title,” High Temp. Sci., vol. 16, pp. $243-250,1983$.

[16] S. A. Hassanzadeh-tabrizi, H. Hosseini, and S. Alizadeh, "In situ synthesis of vanadium carbide - copper nanocomposite by a modified mechanochemical combustion method," Ceram. Int., pp. 1-4, 2016. 
Figures:

Table 1: Chemical Compositions of Materials Used (wt.\%)

\begin{tabular}{ccccccccc}
\hline & $\mathrm{C}$ & $\mathrm{Cr}$ & $\mathrm{Ni}$ & $\mathrm{P}$ & $\mathrm{Si}$ & $\mathrm{Mn}$ & $\mathrm{S}$ & $\mathrm{N}$ \\
\hline 304/304L Plate & 0.022 & 18.15 & 8.05 & 0.033 & 0.44 & 1.72 & 0.0003 & 0.07 \\
304/30L Powder & 0.03 & 18 to 20 & 8 to 12 & 0.045 & 1 & 2 & 0.030 & - \\
\hline
\end{tabular}
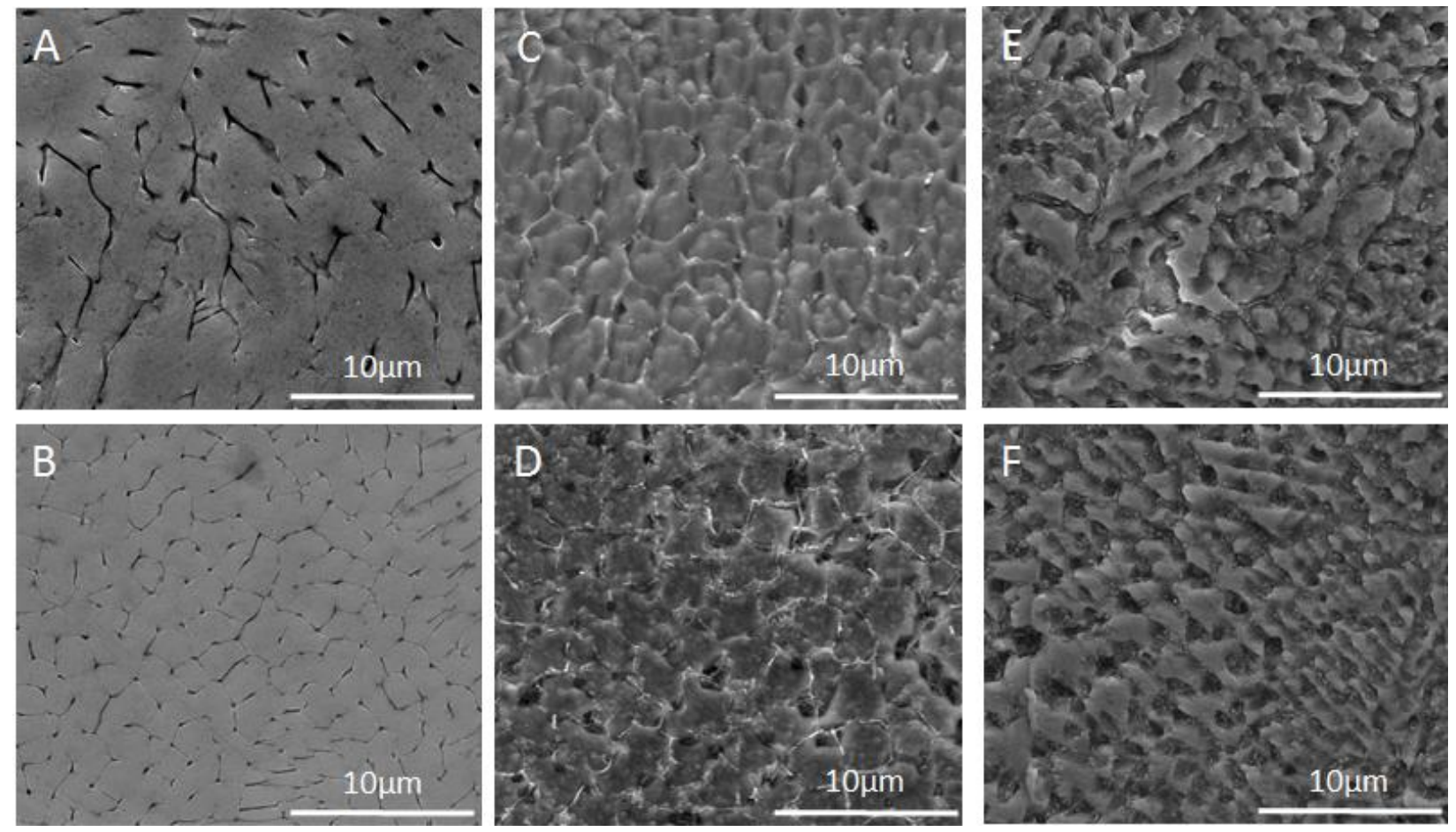

Figure 1: Microstructures of SS304 and NbC coatings. (A) LENS deposited SS304 (B)

LENS deposited SS304 - laser pass (C) $5 \% \mathrm{NbC}$ (D) $5 \% \mathrm{NbC}$ - laser pass (E) $5 \% \mathrm{NbC}$ (F) $5 \% \mathrm{NbC}$ - laser pass 


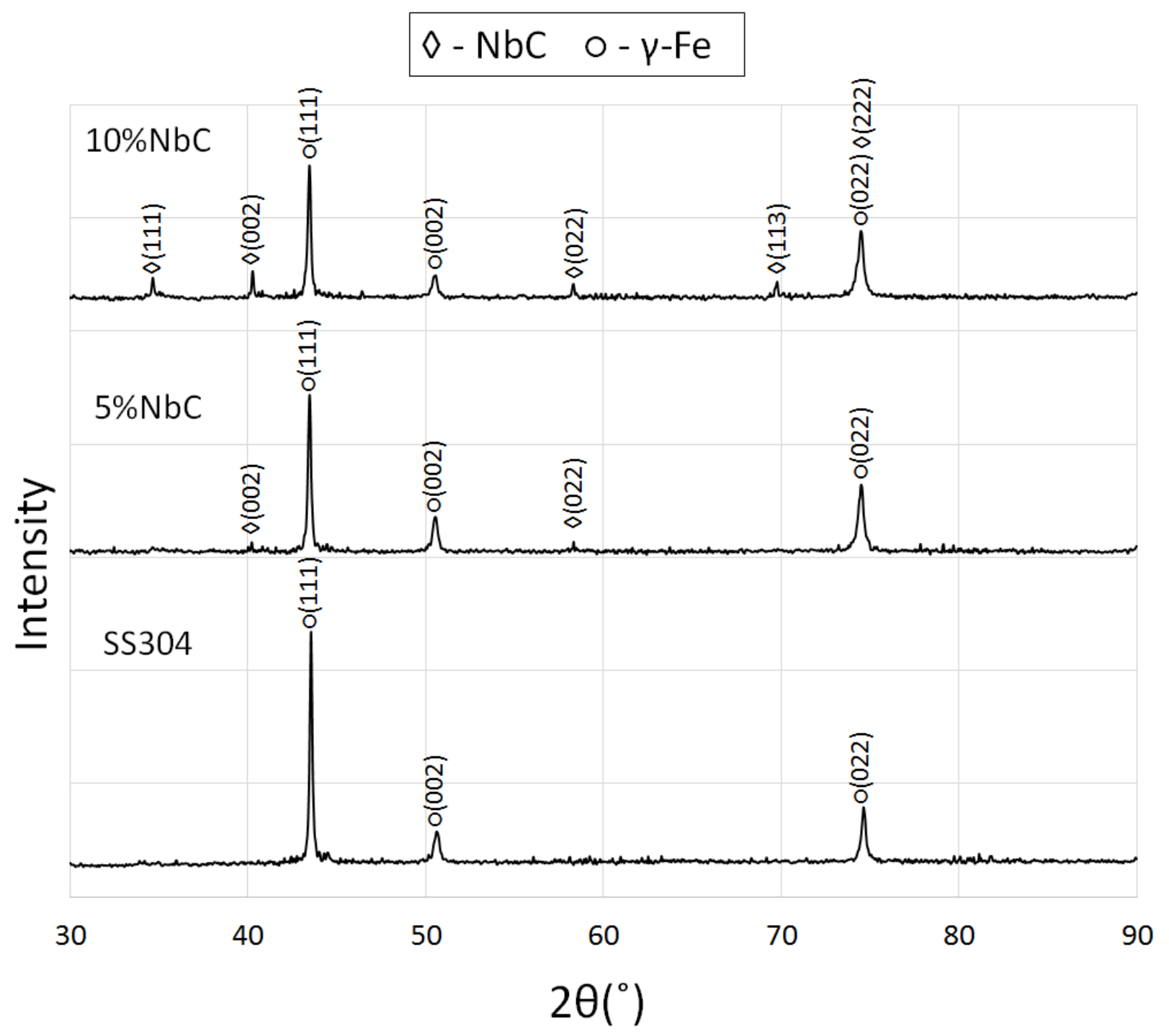

Figure 2: XRD plots of all NbC samples 


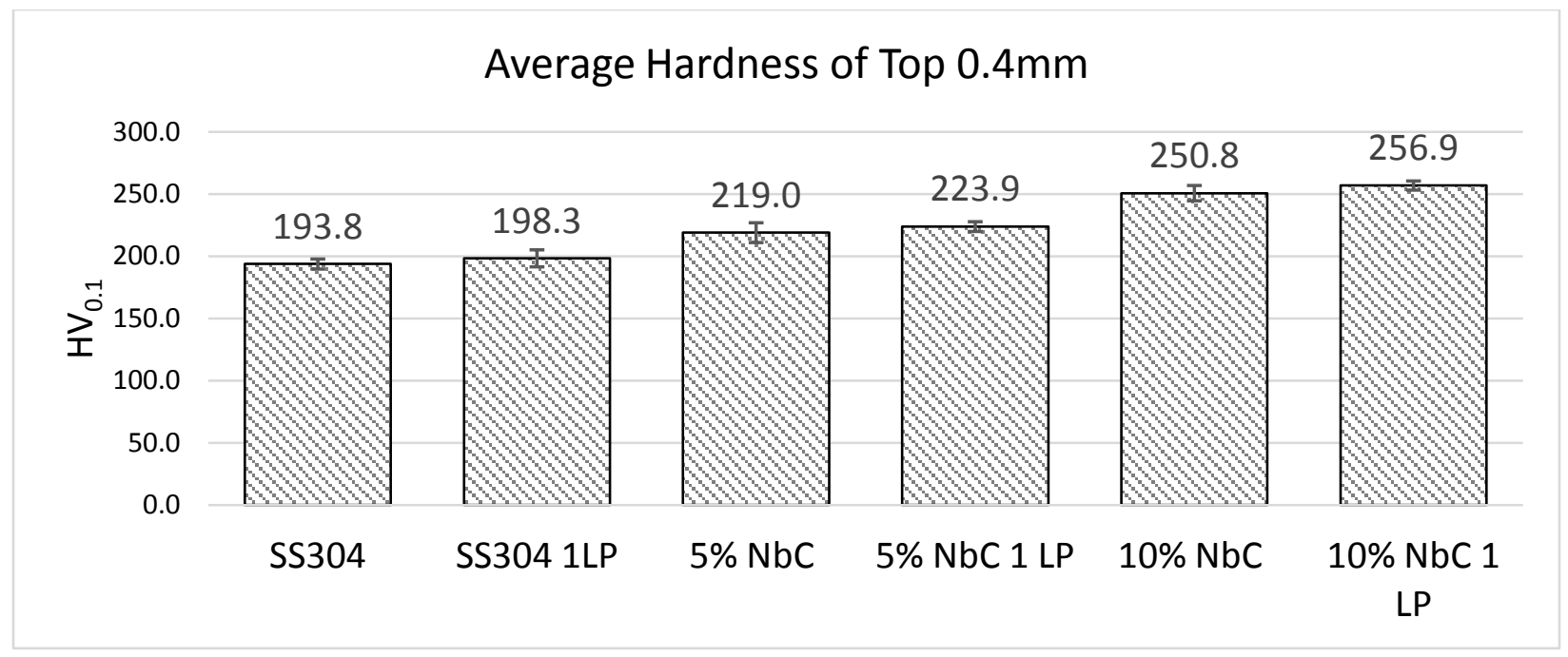

Figure 3: Bar graph of coating hardness

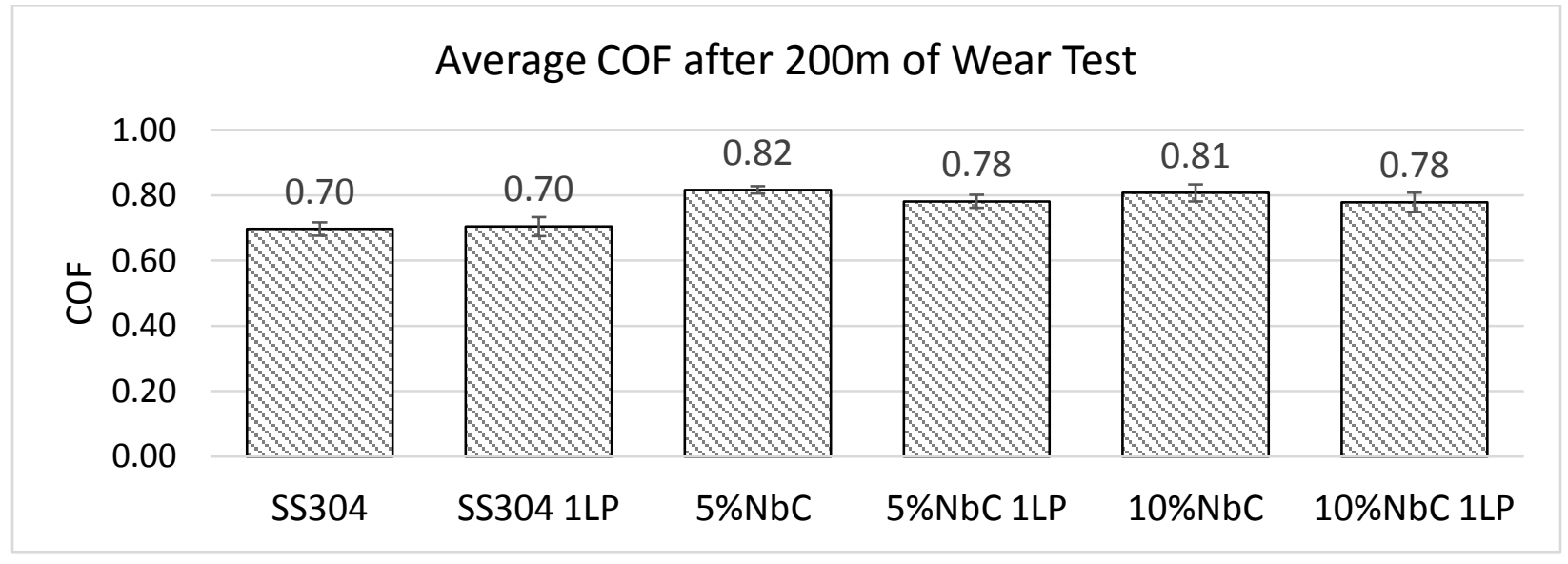

Figure 4: Bar graph of Average COF values after 200m 


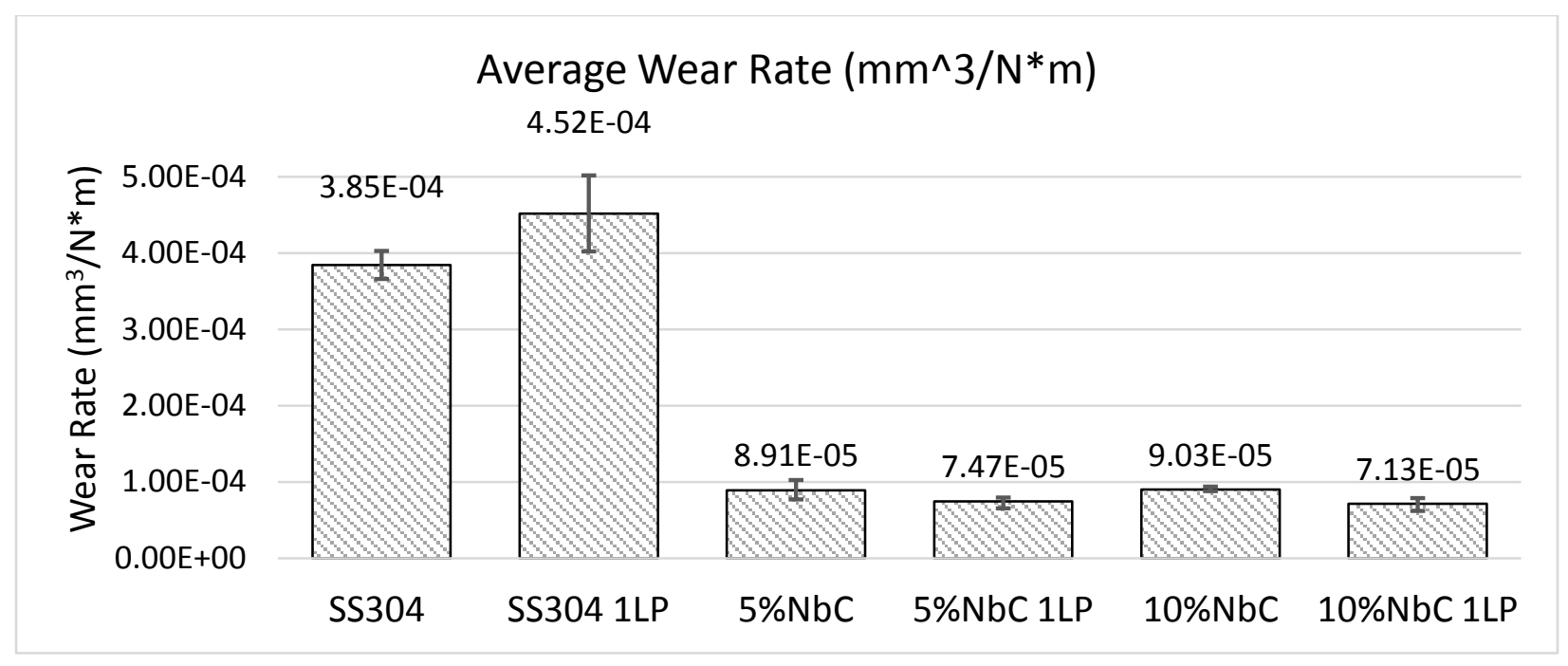

Figure 5: Bar graph of wear rate of coating based on width of wear track 